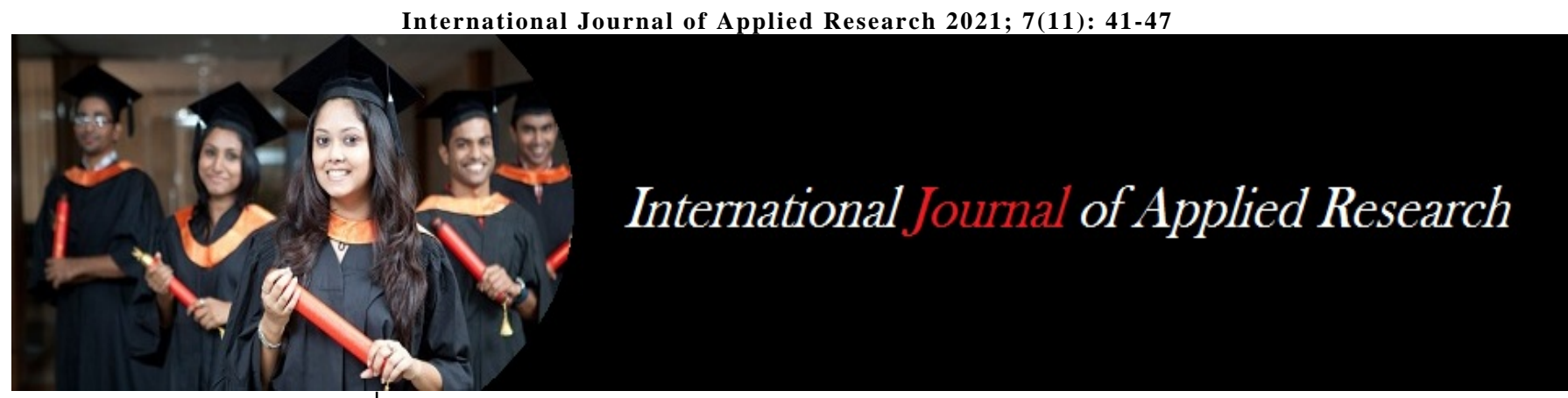

ISSN Print: 2394-7500

ISSN Online: 2394-5869

Impact Factor: 8.4

IJAR 2021; 7(11): 41-47

www.allresearchjournal.com

Received: 25-09-2021

Accepted: 28-10-2021

Dr. Aditi A Wargantiwar

Postgraduate Student,

Department of Periodontology

\& Oral Implantology, Y.C.M.M

\& R.D.F's Dental College \&

Hospital, Ahmednagar,

Maharashtra, India

Dr. Nikesh Moolya

Professor, Department of

Periodontology \& Oral

Implantology, Y.C.M.M. \&

R.D.F's Dental College \&

Hospital, Ahmednagar,

Maharashtra, India

Dr. Nilima Rajhans

Dean, Professor \& HOD,

Department of Periodontology

\& Oral Implantology,

Y.C.M.M. \& R.D.F's Dental

College \& Hospital,

Ahmednagar, Maharashtra,

India

Dr. Supriya Vyavahare

Senior Lecturer, Department of Public Health Dentistry,

Y.C.M.M. \& R.D.F's Dental

College \& Hospital,

Ahmednagar, Maharashtra, India
Corresponding Author:

Dr. Aditi A Wargantiwar

Postgraduate student,

Department of Periodontology

\& Oral Implantology, Y.C.M.M

\& R.D.F's Dental College \&

Hospital, Ahmednagar,

Maharashtra, India

\section{Comparative efficacy of diode laser, Iontophoresis and desensitizing agent in the treatment of dentinal hypersensitivity: A randomized clinical trial}

\author{
Dr. Aditi A Wargantiwar, Dr. Nikesh Moolya, Dr. Nilima Rajhans and \\ Dr. Supriya Vyavahare
}

DOI: https://doi.org/10.22271/allresearch.2021.v7.i11a.9098

\begin{abstract}
Aim: The aim of this randomized clinical trial was to evaluate and compare the clinical efficacy of diode laser in combination with topical Potassium nitrate $\left(\mathrm{KNO}_{3}\right)$ gel, Iontophoresis and $\mathrm{KNO}_{3}$ topical gel alone in the treatment of dentinal Hypersensitivity.

Materials and Methods: 30 systemically healthy patients with Dentinal Hypersensitivity were enrolled in the randomized clinical trial. The patients with dentinal hypersensitivity were randomly allocated into 3groups: Group I was treated with diode laser and $\mathrm{KNO}_{3}$ gel; Group II with Iontophoresis using Sodium Fluoride (NaF) gel and Group III was treated with $\mathrm{KNO}_{3}$ topical gel alone. Sensitivity was recorded using the verbal rating scale before treatment, 10 min after treatment and 7, 15 and 21 days post therapy.

Results: The mean difference among three groups showed a maximum reduction $(-1.100)$ of dentinal hypersensitivity in group I as compared to group III and group II (-.300) after 15 days. On comparison of group II and group III, it showed reduction (-.800) of dentinal hypersensitivity after 15 days. A statistically significant difference was observed among all the three groups. All the groups showed significant reduction in Dentinal Hypersensitivity. However, the use of diode laser with $\mathrm{KNO}_{3}$ gel showed statistically significant reduction in sensitivity $(P<0.05)$ when compared to Iontophoresis and $\mathrm{KNO}_{3}$ topical gel alone
\end{abstract}

Keywords: Dentinal Hypersensitivity, Potassium nitrate $\left(\mathrm{KNO}_{3}\right)$ gel, Iontophoresis, Diode laser, Verbal rating scale.

\section{Introduction}

Dentinal hypersensitivity (DH) is one of the most frequently encountered clinical condition in dental practice. Dentinal Hypersensitivity is defined as a short, sharp pain that arises from exposed dentin in response to non-noxious stimuli, typically thermal, evaporative, tactile, osmotic or chemical that cannot be attributed to any other pathology ${ }^{[1]}$. It is a painful clinical condition that affects $8 \%$ to $57 \%$ in the adult population and is associated with dentin exposure to oral environment ${ }^{[2]}$. The prevalence of $\mathrm{DH}$ is between $60 \%-98 \%$ in patients with periodontitis ${ }^{[3]}$. DH mostly occurs in patients who are between 30 and 40 years old. This condition may affect any tooth, but it mostly affects canines and premolars ${ }^{[4]}$.

$\mathrm{DH}$ can be caused by acidic foods and beverages, trauma, teeth bleaching, professional oral hygiene procedures, poor oral hygiene habits or incorrect brushing techniques with consequent gingival recession that result in dental or periodontal damage. It also include wasting diseases like enamel attrition, erosion, abrasion, corrosion and abfraction etc. Even the removal of orthodontic fixed appliances could expose teeth leading to hypersensitivity ${ }^{[5}$, ${ }^{6}$ In patients with $\mathrm{DH}$, the affected teeth become sensitive to non-harmful environmental stimuli such as gentle touch, mild cold or hot, air-flow stimuli and chemicals (acidic or sweet fruits, foods, drinks) can induce short sharp pain that may affect daily activities including eating, drinking, speaking and tooth brushing ${ }^{[7]}$.

Various modes of treatment at home or in dental office have been tried in the treatment of DH. At home desensitizing products include toothpastes, mouthwashes and chewing gums with active compounds such as sodium fluoride $(\mathrm{NaF})$, potassium nitrate, strontium chloride, 
stannous fluoride, potassium oxalate etc.

In dental office, the use of cavity varnishes, antiinflammatory agents, fluoride compounds, calcium compounds, restorative resins, cyanoacrylate, homeopathic remedies such as Plantago major, propolis, Iontophoresis and lasers is widely recommended ${ }^{[8,9]}$.

Toothpastes containing potassium nitrate have been used since 1980.It diffuses through enamel and dentin into the nerve endings of sensory fibers, reducing the excitability of intradental nerves by inhibiting the movement of sodium and potassium ions around the sensory fibers which results in the suppression of the painful sensation ${ }^{[3,10]}$ According to Kim S. (1986) ${ }^{[11]}$, increase in the concentration of extracellular potassium around the nerve fibers causes their depolarization, avoids repolarization and blocks the axonic action and passage of nerve stimulus, thus inactivating the action potential. Iontophoresis has been found to cause a significant improvement in $70 \%-80 \%$ of patients and caters to most criteria of an ideal desensitizing agent ${ }^{[12,13]}$ It was first described by Pivati et al. in 1747 and first used in the early 1960 s to treat $\mathrm{DH}{ }^{[14,15]}$. With the advent of dental lasers, several lasers like Nd: YAG, Er: YAG, Er, Cr: YSGG and diode have been used in the treatment of $\mathrm{DH}^{[16]}$. Laser provides an innovative and quicker treatment which results in minimal side effects and safe for the patients which appear more satisfied with conventional therapies. The diode laser appears to be the most widely used in daily practice by dentist. Diode Laser has specific wavelengths (655 $\mathrm{nm}$ to $980 \mathrm{~nm}$ ) resulting safe for the patient and causing minimum side effects or damage to the pulp as it is found in case of powerful systems such as Er, Cr:YSGG or Er: YAG lasers ${ }^{[6]}$.

Thus, the aim of this clinical study was to evaluate and compare the clinical efficacy of Potassium nitrate $\left(\mathrm{KNO}_{3}\right)$ topical gel, Iontophoresis and diode laser in combination with topical potassium nitrate $\left(\mathrm{KNO}_{3}\right)$ gel in the treatment of Dentinal Hypersensitivity.

\section{Materials and methods}

This randomized, single-blind, parallel clinical trial was carried out in Department of Periodontology, Y.C.M.M And R.D.F's Dental College and Hospital, Ahmednagar. Randomization of patients into each group was done by investigator using lottery method, 10 each. The patients enrolled for this study were selected from the outpatient department of Periodontology. 30 systemically healthy patients with chief complaint of DH were enrolled for the study. The study was approved from the institutional ethics committee. The written informed consent was signed by all patients.

\section{Inclusion criteria}

1. Systemically healthy patients

2. Patients age between 35 - 60 years

3. Patients having minimum of 20 permanent teeth

4. No scaling or any dental procedures carried out in last 6 months.

5. Patients with clinically elicitable dentinal hypersensitivity who were reliable in their response to test measurements

\section{Exclusion criteria}

1. Those who had used any desensitizing paste or mouthwash during the last 6 months

2. Pregnant and lactating mothers
3. Smokers

4. Patients with cracked teeth, large carious lesions or restored teeth

The patients with dentinal hypersensitivity were randomly allocated into three groups. Before treatment, all the patients underwent phase I periodontal therapy i.e scaling and root planning followed by oral hygiene instructions. The degree of sensitivity before and after treatment was determined qualitatively with an air stimulus. To check the air stimulus, the selected tooth was isolated, dried and a jet of air was applied from a distance of $1 \mathrm{~cm}$ for $1 \mathrm{~s}$ and response to air stimuli was recorded.

\section{Clinical parameters}

Dentinal Hypersensitivity was recorded using the verbal rating scale (VRS) ${ }^{[17]}$ before treatment, 10min after treatment and 7,15 and 21 days post therapy.

Verbal rating scale (VRS) is a four-point scale where $0=$ no sensitivity, 1 = mild sensitivity, 2 = moderate sensitivity, 3 = severe sensitivity, 4 = very severe sensitivity was used after withdrawal of the stimulus ${ }^{[17]}$.

The distance between identifiable CEJ to gingival margin was recorded by CAL (Clinical Attachment Level) measurement before treatment, 7, 15 and 21 days.

\section{Treatment procedure}

A total of 30 patients with hypersensitivity teeth due to periodontal disease or wasting disease (abrasion, attrition, erosion, abreaction at cervical third area) were selected. Three teeth (single rooted or multirooted) were selected per patient.

\section{Group I: Diode laser + Potassium nitrate topical gel:}

The selected teeth were isolated with cotton rolls and topical $\mathrm{KNO}_{3}$ gel was applied with a cotton tip applicator onto the affected area and left in place for $1 \mathrm{~min}$. Diode laser (Doctor Smile, Italy) having a wavelength of $980 \mathrm{~nm}$ was irradiated in noncontact, continuous mode with a power from $0.2 \mathrm{~W}$ to $0.6 \mathrm{~W}$ for 5 consecutive $20 \mathrm{sec}$ intervals on the selected teeth. Then, $\mathrm{KNO}_{3}$ gel was removed, repeated the procedure (from $0.2 \mathrm{~W}$ to $0.6 \mathrm{~W}$ ) by brushing the fiber in contact over selected teeth and VRS score recorded.

\section{Group II: Iontophoresis treatment group:}

The sensitive teeth were treated with dental Iontophoresis unit (Jonofluor ${ }^{\circledR}$ Praxis Master, Dental Medical, Italy). The selected teeth were isolated with cotton rolls and dried. A sponge with thin layer of Sodium fluoride (NaF) gel was applied in a tray. An autoclaved tray with disposable sponges applied with $\mathrm{NaF}$ gel was to keep in contact with affected teeth surfaces. The metal electrode with red spiral was held in the patient's hand. The metal electrode with black spiral was kept in contact with rectangular slot in the tray. Resistance knob was turned clock wise. Then, the polarity and time was pre-set at $2 \mathrm{~mA}$ output current for 2.5 minutes. When the set time was over, the appliance gave a beep and procedure was stopped. Then, a tray with the electrode and sponge was removed from the patients dental arch. The teeth were evaluated 10 mins after the treatment and VRS score recorded.

\section{Group III: Potassium nitrate topical gel only}

The selected teeth were isolated with cotton rolls and $\mathrm{KNO}_{3}$ gel (Orogard Gel, Alkem Laboratories Ltd., India) was applied with a cotton tip applicator onto the affected area 
and left in place for $1 \mathrm{~min}$. The teeth were evaluated $10 \mathrm{~min}$ after the treatment and VRS score recorded.

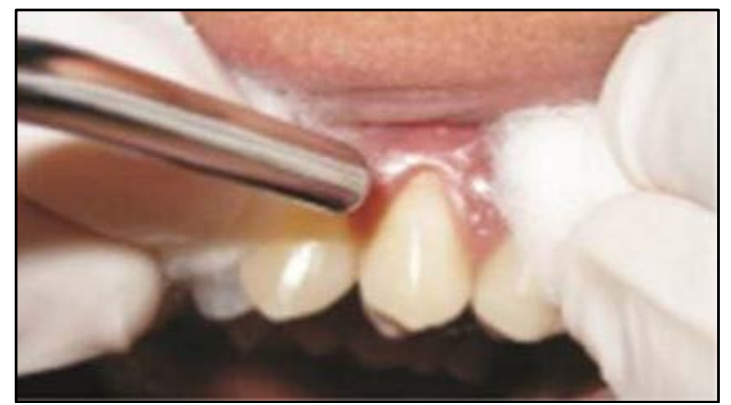

Fig 1: Dentin hypersensitivity checked by jet of air by three way syringe

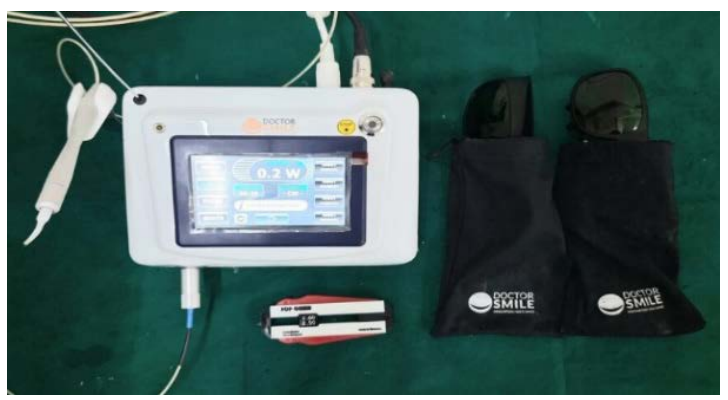

Fig 2: Diode Laser (Doctor Smile)

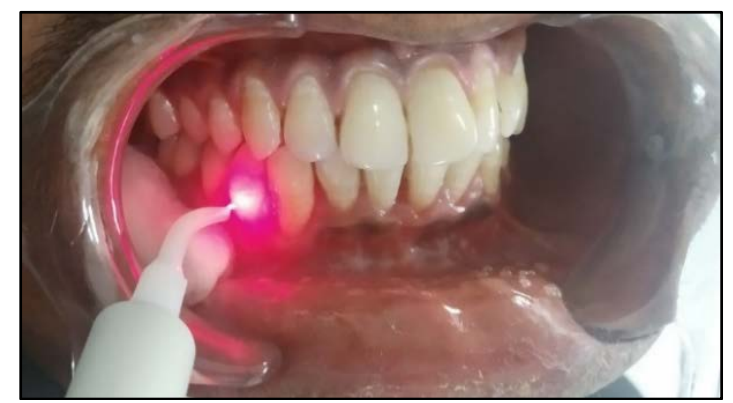

Fig 3: Diode laser desensitization

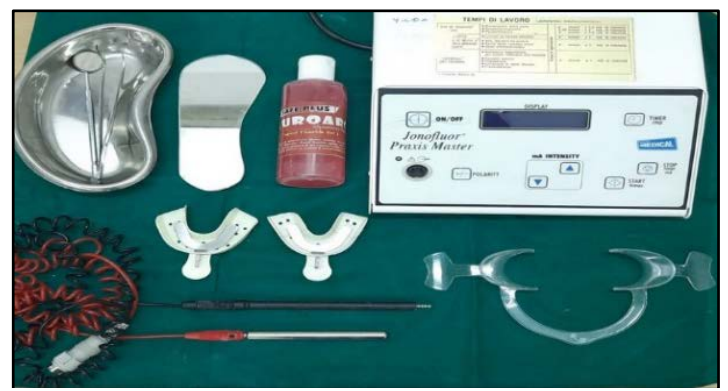

Fig 4: Ionophoresis Unit (Jonofluor® Praxis Master)

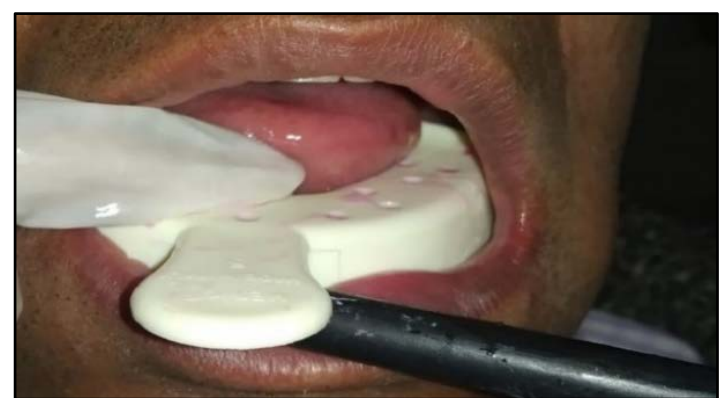

Fig 5: Iontophoresis was done

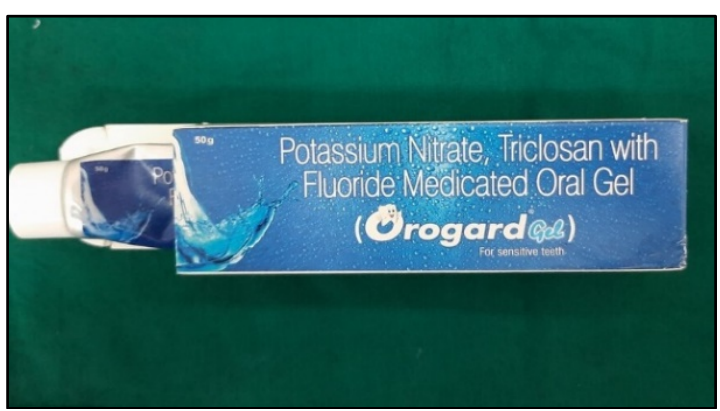

Fig 6: Potassium nitrate topical gel (Oragard gel)

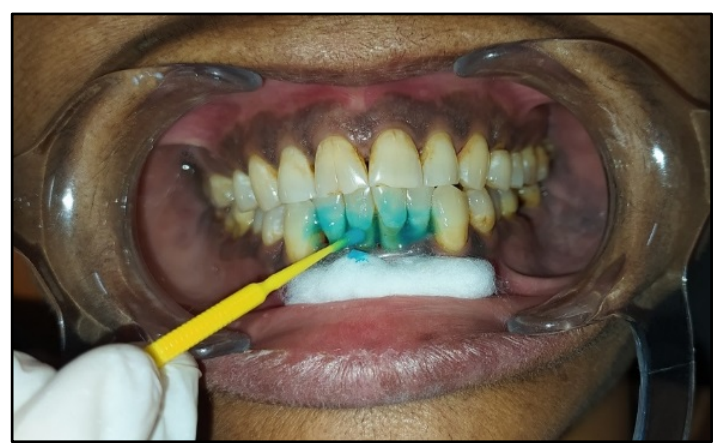

Fig 7: Potassium nitrate topical gel application

\section{Recall visits}

All patients were recalled 10mins after treatment and 7, 15 and 21 days after therapy. At each visit, the above mentioned procedure was repeated and VRS score, CAL measurements were recorded. All patients had received oral hygiene instructions at each visit. No oral prophylaxis was performed at the recall visits until the end of evaluation phase. Subjective signs such as ulceration, burning sensation, allergic reaction and taste alterations along with objective signs such as redness of mucosa and staining of teeth were checked with none being reported.

\section{Statistical analysis}

The statistical analysis was carried out using one-way analysis of variance test. The data were entered in Microsoft Excel and analyzed using statistical package for social science (SPSS) version 22 software. Kruskal Wallis test was used to determine statistically significant differences between the groups and Post hoc test was used for intergroup comparison of 3 groups. The results were averaged (mean \pm standard deviation) for continuous data. $\mathrm{P}<0.05$ was considered as statistically significant.

\section{Results}

All test teeth presented DH before the desensitizing treatment i.e., at the baseline and $10 \mathrm{~min}$ after treatment. The levels of hypersensitivity were not statistically significant among all 3 groups [Table. 1] But, on the $7^{\text {th }}$ and $15^{\text {th }}$ day, levels of hypersensitivity were statistically significant among all 3 groups. [Table no.1] On inter-group comparison, Group I, Group II and Group III did not show a significant reduction at the baseline and $10 \mathrm{~min}$ after treatment. On $7^{\text {th }}$ day and $15^{\text {th }}$ day, Group I showed significant reduction as compared to Group III followed by Group II [Table 2].On $7^{\text {th }}$ and $15^{\text {th }}$ day, Group I showed significant reduction in VRS score as compared to Group III followed by Group II [Figure no.8] [Figure no.9] On $21^{\text {th }}$ day, three groups showed almost similar mean differences for DH with maximum reduction (-.700) in group I. 
Table 1: Kruskal-Wallis Test for Dentin hypersensitivity in 3 Groups on baseline, $10 \mathrm{~min}$ after T/t, $7^{\text {th }}, 15^{\text {th }}$ and $21^{\text {st }}$ day

\begin{tabular}{|c|c|c|c|c|c|}
\hline \multicolumn{6}{|c|}{ Ranks } \\
\hline & Groups & $\mathrm{N}$ & Mean Rank & $\mathrm{X}^{2}$ & P value \\
\hline \multirow{4}{*}{ Baseline } & Diode Laser & 10 & 17.50 & \multirow{4}{*}{1.825} & \multirow{4}{*}{.402} \\
\hline & Iontophoresis & 10 & 16.20 & & \\
\hline & Potassium Nitrate & 10 & 12.80 & & \\
\hline & Total & 30 & & & \\
\hline \multirow{4}{*}{$10 \mathrm{~min}$} & Diode Laser & 10 & 15.50 & \multirow{4}{*}{1.065} & \multirow{4}{*}{.587} \\
\hline & Iontophoresis & 10 & 13.60 & & \\
\hline & Potassium Nitrate & 10 & 17.40 & & \\
\hline & Total & 30 & & & \\
\hline \multirow{4}{*}{7 days } & Diode Laser & 10 & 11.45 & \multirow{4}{*}{6.204} & \multirow{4}{*}{.045} \\
\hline & Iontophoresis & 10 & 14.60 & & \\
\hline & Potassium Nitrate & 10 & 20.45 & & \\
\hline & Total & 30 & & & \\
\hline \multirow{4}{*}{ 15days } & Diode Laser & 10 & 11.25 & \multirow{4}{*}{7.101} & \multirow{4}{*}{.029} \\
\hline & Iontophoresis & 10 & 14.30 & & \\
\hline & Potassium Nitrate & 10 & 20.95 & & \\
\hline & Total & 30 & & & \\
\hline \multirow{4}{*}{ 21days } & Diode Laser & 10 & 12.05 & \multirow{4}{*}{4.790} & \multirow{4}{*}{.091} \\
\hline & Iontophoresis & 10 & 14.75 & & \\
\hline & Potassium Nitrate & 10 & 19.70 & & \\
\hline & Total & 30 & & & \\
\hline
\end{tabular}

Table 2: Post Hoc Test for inter-group comparison of three groups

\begin{tabular}{|c|c|c|c|c|c|c|}
\hline \multirow{2}{*}{$\begin{array}{c}\text { Dependent } \\
\text { Variable }\end{array}$} & \multirow[t]{2}{*}{ (I) Groups } & \multirow[t]{2}{*}{ (J) Groups } & \multirow[t]{2}{*}{ Mean Difference (I-J) } & \multirow[t]{2}{*}{ P value } & \multicolumn{2}{|c|}{ 95\% Confidence Interval } \\
\hline & & & & & Lower Bound & Upper Bound \\
\hline \multirow[t]{3}{*}{ 10min } & \multirow[t]{2}{*}{ Diode Laser } & Potassium Nitrate & -.200 & .849 & -1.11 & .71 \\
\hline & & Iontophoresis & .200 & .849 & -.71 & 1.11 \\
\hline & Iontophoresis & Potassium Nitrate & -.400 & .525 & -1.31 & .51 \\
\hline \multirow[t]{3}{*}{7 days } & \multirow[t]{2}{*}{ Diode Laser } & Potassium Nitrate & $-.900^{*}$ & .028 & -1.71 & $-.09^{*}$ \\
\hline & & Iontophoresis & -.300 & .635 & -1.11 & .51 \\
\hline & Iontophoresis & Potassium Nitrate & -.600 & .179 & -1.41 & .21 \\
\hline \multirow[t]{3}{*}{ 15days } & \multirow{2}{*}{ Diode Laser } & Potassium Nitrate & $-1.100^{*}$ & .016 & -2.02 & $-.18^{*}$ \\
\hline & & Iontophoresis & -.300 & .700 & -1.22 & .62 \\
\hline & Iontophoresis & Potassium Nitrate & -.800 & .096 & -1.72 & .12 \\
\hline \multirow[t]{3}{*}{ 21days } & \multirow[t]{2}{*}{ Diode Laser } & Potassium Nitrate & $-.700^{*}$ & .048 & -1.39 & $-.01^{*}$ \\
\hline & & Iontophoresis & -.200 & .758 & -.89 & .49 \\
\hline & Iontophoresis & Potassium Nitrate & -.500 & .194 & -1.19 & .19 \\
\hline
\end{tabular}

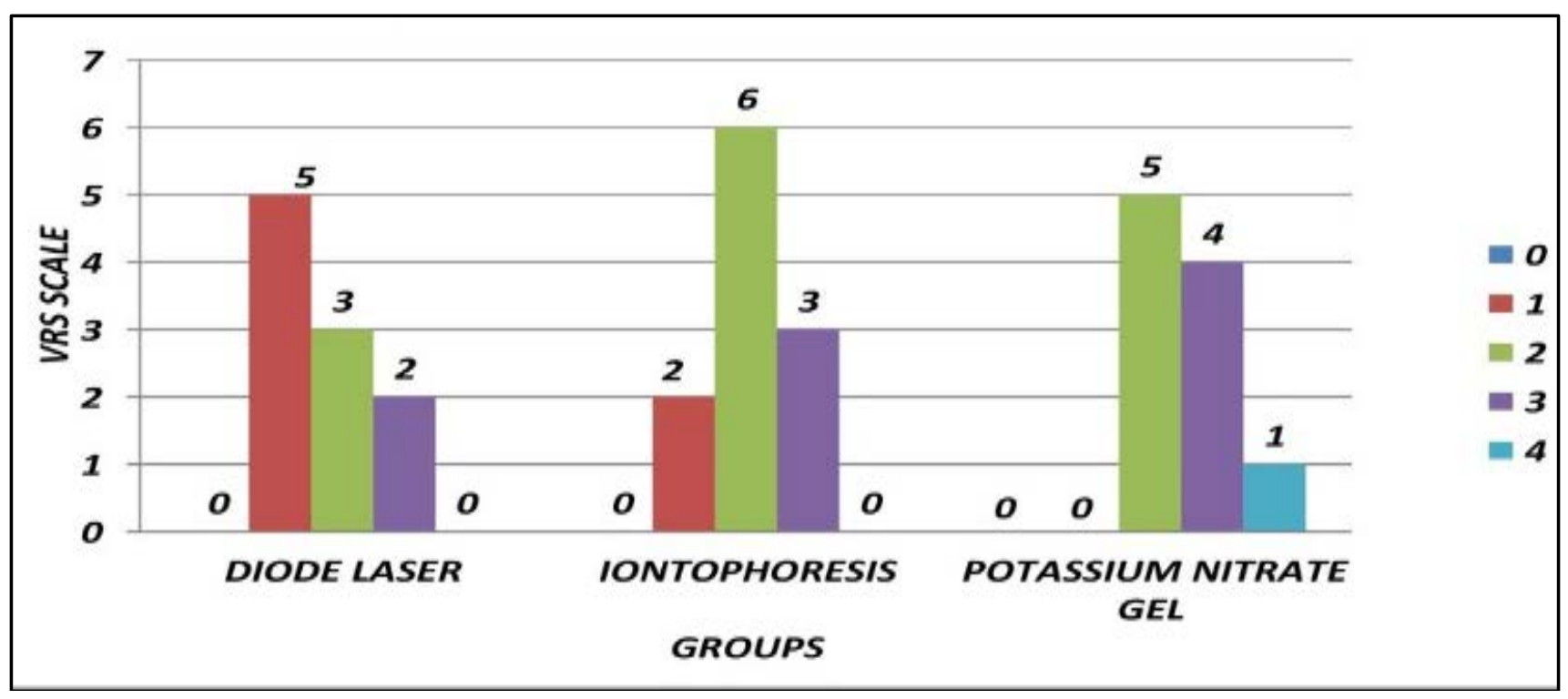

Fig 8: Comparison for three groups using severity of hypersensitivity on VRS scale 


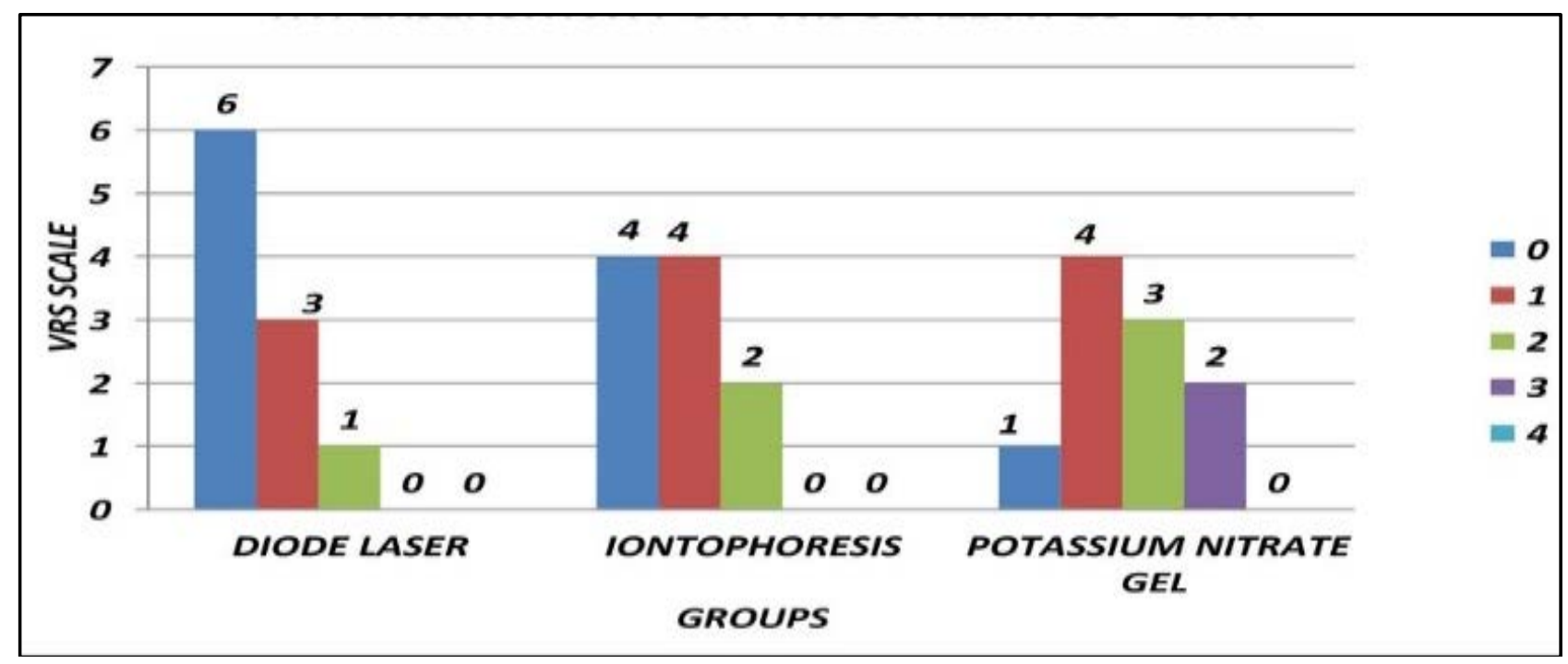

Fig 9: Comparison for three groups using severity of hypersensitivity on VRS scale at $15^{\text {th }}$ day

\section{Discussion}

Curro has stated that tooth hypersensitivity should now be considered in the spectrum of pain as it can fit the criteria of several pain terms described by Marsky for the International Association of Study of Pain (IASP). The term should be allodontia to describe tooth hypersensitivity ${ }^{[18]}$. So far, there has been no gold standard for the treatment of $\mathrm{DH}$ and thus it persists as a chronic dental problem. The most probable methods of eliminating the $\mathrm{DH}$ appears to be disruption of the transmission of stimuli to the nerve terminals that accompany the odontoblastic processes by minimizing the dentinal fluid movement within the tubules, which can be obtained either by constriction or by occlusion of tubule orifices ${ }^{[19]}$. In light of the hydrodynamic theory, many of the treatment modalities such as simple-desensitizing tooth pastes, intermediate-iontophoresis and to complex ones such as lasers and tissue graft aim to reduce sensitivity by blocking the dentinal tubules ${ }^{[15,13]}$.

Randomized clinical trial was used in the present study to facilitate the comparison of the three treatment methods by reducing the bias. This study was conducted in the age group of 35-60 yrs as the peak prevalence of DH occurs in that group. Declining hypersensitivity symptoms after the age of 60yrs may be due to the development of secondary or sclerotic dentine which is not affected by mechanical forces. There is no reopening of dentinal tubules which helps in maintaining the desensitizing effect. Also, tooth wear and periodontal disease become more common with ageing ${ }^{[20]}$. Patients with exposed root surface and inadequate plaque control are more likely to have DH. So, in this study, scaling was performed on the selected patients and recalled on $7^{\text {th }}$, $15^{\text {th }}$ and $21^{\text {th }}$ day based on study done by David H. Pasley et al. [21] stated that the smear layer created during manipulation of root surface may last for 5-7 days.

The diagnosis of DH was confirmed based on the positive response of the patients followed by clinical examination in which an air blast from a three way syringe was used as a stimulus test based on study done by Liu et al. ${ }^{[22]}$ reported that $92 \%$ of sensitive subjects were sensitive to an air blast stimulus. The verbal rating scale (VRS) was used to assess the various degrees of hypersensitivity. A VRS is a four point scale representing the limits of sensitivity a patient might experience from an external stimulus. It is use to indicate their level of pain in response to hypersensitive stimuli. Recently, there is no single method to assess dentin hypersensitivity which is considered as ideal method. So, VRS was used for assessment of hypersensitivity. Clinical Attachment Level (CAL) measurements were taken of selected teeth to assess the gingival recession which results in DH. Three teeth (single rooted or multirooted) were evaluated per patient with hypersensitivity due to periodontal disease (gingival recession) or wasting disease (abrasion, attrition, erosion, abreaction at cervical third area). Based on the present understanding of hypersensitivity and methods of assessment, this clinical study was carried out employing three methods such as diode laser with $\mathrm{KNO}_{3}$ gel, Iontophoresis with $\mathrm{NaF}$ application and $5 \%$ potassium nitrate on the basis of the studies done by Nandkumar A and Iyer $\mathrm{VH}^{[31]}$ (diode laser $+\mathrm{KNO}_{3}$ gel), Mangalekar SB et al. ${ }^{[18]}$ (for Iontophoresis) and Attar NB et al. ${ }^{[23]}$ (5\% potassium nitrate) and evaluated their clinical efficiency.

Potassium nitrate is the most commonly used desensitizing agent (GIII). The 5\% potassium nitrate gel is used effectively for the treatment of sensitivity as it reduces immediate pain score. Potassium ions in dentifrice act directly on intraductal nerves by raising extracellular potassium ion concentration sufficiently to prevent action potential generation by axonal accommodation. It desensitizes the tooth by tooth's neural and vascular components rather than diminishing the dentinal tubule. The potassium nitrate penetrates enamel and dentin. It shows a depolarizing effect on neural conduction which would result in diminished nerve fiber response to stimulation. Its penetration depends on the concentration and viscosity ${ }^{[18 \text {, }}$ 23]. In this study, statistically significant reduction of $\mathrm{DH}$ with $\mathrm{KNO}_{3}$ gel (GIII) was seen on $21^{\text {th }}$ day.

In present study, $\mathrm{NaF}$ was used in combination with Iontophoresis (GII). Mangalekar SB et al. ${ }^{[18]}$ reported that Iontophoresis with $\mathrm{NaF}$ application showed better desensitising effect than potassium nitrate and potassium oxalate. McBride et al. ${ }^{[24]}$. Reported that the fluoride concentration is two times more in teeth treated with Iontophoresis than in topically treated teeth. Iontophoresis acts by influencing ionic motion by electric currents, enhancing ion uptake by the dentinal tubules which results in desensitization. 
$\mathrm{NaF}$ gel was chosen as a desensitizing agent for Iontophoresis because $\mathrm{NaF}$ exerts a beneficial, desensitizing effect as it is readily absorbed by dental hard tissues and fluoride ions thus adsorbed under walls of the dentinal tubules as well as on the surface of calcium forms an insoluble compound calcium fluoride $\left(\mathrm{CaF}_{2}\right)$ with the tooth substance. It forms a new physical barrier which narrows the dentinal tubules, reducing its permeability. It was discovered that a reaction between fluoride and the free ions of some electrolytes such as calcium make these ions unavailable for the normal mechanism of pain conduction. Single application of $\mathrm{NaF}$ is less effective as it forms small sized calcium fluoride crystals (approximately $0.05 \mu \mathrm{m}$ ) which can be easily soluble in saliva ${ }^{[15,16]}$.

In this study, Diode laser was also used in combination with $\mathrm{KNO}_{3}$ gel (GI). Compared to conventional desensitizing agents, the laser treatment showed rapid results with less application time and more quickly for the patient. In this study, this group showed the highest reduction of $\mathrm{DH}$ in particular for air blast stimulation. Even though several lasers such as Nd: YAG, Er: YAG, Cr: YSGG lasers have been used, the diode laser has specific wavelengths resulting very safe for the patient. It is easily available and economical. So, the diode laser have become more popular and appears to be the most widely used in everyday practice by dentists ${ }^{[6,25]}$. An innovative $980-n m$ diode wavelength laser used as it is a high-energy laser with low purchase and maintenance costs as well as greater versatility because of its compact size. The rapid sealing of exposed dentinal tubules and its safety to odontoblasts and pulp tissue is another feature seen with diode laser ${ }^{[26]}$.

Brugnera et al. ${ }^{[27]}$ showed the immediate analgesic effect by using a diode laser. According to Matsumoto et al. ${ }^{[28]}$ when diode lasers were used for the treatment of $\mathrm{DH}$, a gradual decrease in tactile stimuli (TS) and air blast stimulation was noticed on days 15 and 30, when compared to that at baseline and observed 85\% improvement in DH. Kumazaki et al. [29] reported that improvement of $69.2 \%$ was seen in the group treated with lasers when compared with other group. Aun CA et al. ${ }^{[30]}$ reported success in laser-irradiated teeth in $98 \%$ of their cases. Nandkumar A and Iyer VH ${ }^{\text {[31] }}$ suggested that diode lasers were able to seal the dentin tubules. DLs can be used directly by direct application of lasers alone and indirectly by the use of some desensitizing agents with laser application. The better effects of combined treatment may be due to the higher $\mathrm{KNO}_{3}$ gel adhesion to the dentinal tubules combined with laser energy.

The mechanism of action of diode lasers in hypersensitivity is the depressed transmission of nerve impulses within the dental pulp rather than alterations in the exposed dentine surface as observed in other treatment modalities. Laser stimulates the odontoblasts, produces reparatory irregular dentin and obliterates the dentinal tubules which reduces the dentinal hypersensitivity ${ }^{[32]}$. Patil AR. et al. ${ }^{[15]}$ reported that the comparative SEM findings showed statistically significant difference in percentage of completely occluded tubules in the laser group. Liu Y et al. ${ }^{[26]}$ who demonstrated that 2 Watt/Continuous wave $\left(166 \mathrm{~J} / \mathrm{cm}^{2}\right)$ was suitable parameter for a $980 \mathrm{~nm}$ diode laser to seal dentinal tubules without excess melting of the dentin.

In this conducted study, the levels of hypersensitivity were not statistically significant among all three groups at the baseline and $10 \mathrm{~min}$ after treatment. But, on the $7^{\text {th }}$ and $15^{\text {th }}$ day, levels of hypersensitivity were statistically significant among all 3 groups. On inter-group comparison, Group I, Group II and Group III did not show a significant reduction at the baseline and $10 \mathrm{~min}$ after treatment. On $7^{\text {th }}$ day and $15^{\text {th }}$ day, Group I showed significant reduction of $\mathrm{DH}$ as compared to Group III followed by Group II i.e the mean difference among three groups showed a maximum reduction of $\mathrm{DH}$ in group I as compared to group III and group II after 15 days. On $21^{\text {th }}$ day, three groups showed almost similar results for $\mathrm{DH}$ with maximum reduction in group I. On $7^{\text {th }}$ and $15^{\text {th }}$ day, Group I showed significant reduction in VRS score as compared to Group III followed by Group II. This advocates the use of lasers as an effective and acceptable treatment modality for the faster reduction of DH.

Recently, researches have been made in various areas of management of DH. This include advances in toothbrush technology, abrasively of toothpastes (Relative Dentin Abrasion scale), new agents such as Pro-Argin, Nova Min ${ }^{\circledR}$, improved material science such as Nano composites and nanoionomers, improvements in periodontal flap procedures and QoL (quality of life) of patients having $\mathrm{DH}$. Though $\mathrm{DH}$ is an old problem, it still remains an enigma, poorly understood and prevalence of DH remains high. In spite of the vast literature on this subject and the new advances in treatment, there is still lack of a consensus among researchers on the ideal treatment modality. So, a lot of research is still ongoing in achieving the ultimate goal in the treatment of DH which should give immediate and permanent relief of pain ${ }^{[33]}$.

The limitation of this study was the short observation time after treatment. The sample size was relatively small. The method and interpretation of pain assessment elicited from stimuli and nature of response and variability of patient's ability to express a given response could also introduce some bias which is inevitable.

\section{Conclusion}

The present study concluded that Diode Lasers associated with $\mathrm{KNO}_{3}$ topical gel showed significantly greater reduction of $\mathrm{DH}$ followed by Iontophoresis and $\mathrm{KNO}_{3}$ topical gel only.

\section{Practical implications}

It has been well documented that dentinal hypersensitivity can be reduced by using various treatment modalities like desensitizing agents, Iontophoresis, diode laser etc. But, the exposure to non-harmful environmental stimuli on daily basis may increase the dentinal hypersensitivity. So, identification of causing factors, reduction of causal stimuli, educating the patient, reassessment of pain and proper management of the condition shows greater reduction of dentinal hypersensitivity.

\section{Conflicts of interest}

There are no conflicts of interest.

\section{Financial support and sponsorship: Nil.}

\section{References}

1. Canadian Advisory Board on Dentin Hypersensitivity. Consensus-based recommendations for the diagnosis and management of dentin hypersensitivity. Journal (Canadian Dental Association). 2003 Apr; 69 (4):221-6. 
2. Markowitz K, Pashley DH. Personal reflections on a sensitive subject. Journal of dental research 2007;86(4):292-5.

3. Orchardson R, Gillam DG. Managing dentin hypersensitivity. The Journal of the American Dental Association 2006;137(7):990-8.

4. Addy M, Mostafa P, Newcombe RG. Dentine hypersensitivity: the distribution of recession, sensitivity and plaque. Journal of Dentistry 1987;15(6):242-8.

5. Liu XX, Tenenbaum HC, Wilder RS, Quock R, Hewlett ER, Ren YF. Pathogenesis, diagnosis and management of dentin hypersensitivity: an evidence-based overview for dental practitioners. BMC Oral Health 2020;20(1):1-0.

6. Biagi R, Cossellu G, Sarcina M, Pizzamiglio IT, Farronato G. Laser-assisted treatment of dentinal hypersensitivity: a literature review. Annali di stomatologia 2015;6(3-4):75

7. Lima TC, Vieira-Barbosa NM, Grasielle de Sá Azevedo C, de Matos FR, Douglas de Oliveira DW, et al. Oral health-related quality of life before and after treatment of dentin hypersensitivity with cyanoacrylate and laser. Journal of periodontology 2017;88(2):166-72

8. Irudaya Nirmala J, Ramakrishnan T, Sivaranjani P, Shobana P, Manisundar N, Ebenezar M. Iontophoresis a boon for treatment of dentinal hypersensitivity: case report. Int J Cur Res Rev 2016;8(23):16.

9. Gillam DG, Orchardson R. Advances in the treatment of root dentine sensitivity: mechanisms and treatment principles. Endodontic Topics 2006;13(1):13-33.

10. Pierote JJ, Prieto LT, Dias CT, CÂmara JV, Lima DA, Aguiar FH, et al. Effects of desensitizing products on the reduction of pain sensitivity caused by in-office tooth bleaching: a 24-week follow-up. Journal of Applied Oral Science 2020, 28.

11. Kim S. Hypersensitive teeth: desensitization of pulpal sensory nerves. Journal of endodontics 1986;12(10):482-5.

12. Lutins ND, Greco GW, McFall Jr WT. Effectiveness of sodium fluoride on tooth hypersensitivity with and without iontophoresis. Journal of periodontology 1984;55(5):285-8.

13. Kumar S, Thomas BS, Gupta K, Guddattu V, Alexander M. Iontophoresis and topical application of $8 \%$ arginine-calcium carbonate to treat dentinal hypersensitivity. Nigerian journal of clinical practice 2018;21(8):1029.

14. Helmstädter A. The history of electrically-assisted transdermal drug delivery (" iontophoresis"). Die Pharmazie 2001;56(7):583-7.

15. Patil AR, Varma S, Suragimath G, Abbayya K, Zope SA, Kale V. Comparative evaluation of efficacy of iontophoresis with $0.33 \%$ sodium fluoride gel and diode laser alone on occlusion of dentinal tubules. Journal of clinical and diagnostic research: JCDR 2017;11(8):ZC123.

16. Ipci SD, Cakar G, Kuru B, Yilmaz S. Clinical evaluation of lasers and sodium fluoride gel in the treatment of dentine hypersensitivity. Photomedicine and Laser Surgery 2009;27(1):85-91.

17. Rocha MO, Cruz AA, Santos DO, Douglas-DE-Oliveira DW, Flecha OD, Gonçalves PF. Sensitivity and specificity of assessment scales of dentin hypersensitivity-an accuracy study. Brazilian oral research 2020, 34.

18. Mangalekar SB. Comparative assessment of efficacy of single application of dipotassium oxalate, Potassium nitrate and sodium fluoride with iontophoresis in the treatment of hypersensitive teeth: An in-vitro and invivo study. International Journal of Contemporary Dentistry 2010;1(3).

19. Jalaluddin M, Almalki SA. Evaluation of the Efficacy of Three Different Treatment Modalities in the Management of Dentinal Hypersensitivity: A Comparative Study 2019, 2-6.

20. Jain A, Rao J, Pal N, Singh A. Effectiveness of fluoride varnish, diode laser, and their combination in treatment of dentin hypersensitivity: A randomized split - mouth clinical trial 2020.

21. David Pasley $\mathrm{H}$, et al. Dentin permeability, dentin sensitivity and treatment through tubule occlusion" : J. Periodontol 1993;64:1045-1051.

22. Chrysanthakopoulos NA. Prevalence of Dentine Hypersensitivity in a General Dental Practice in Greece 2011;3(5).

23. Attar NB, Gaikwad RP, Banodkar AB, Sethna GD. A clinical trial to evaluate the efficacy of $5 \%$ potassium nitrate gel on sensitivity during ultrasonic scaling. Journal of Dental Research and Review 2019;6(1):9.

24. McBride MA, Gilpatrick RO, Fowler WL. The effectiveness of sodium fluoride iontophoresis in patients with sensitive teeth. Quintessence International 1991;22(8).

25. Ladalardo TC, Pinheiro A, Campos RA, Brugnera Júnior A, Zanin F, Albernaz PL, Weckx LL. Laser therapy in the treatment of dentine hypersensitivity. Brazilian dental journal 2004;15(2):144-50.

26. Liu Y, Gao J, Gao Y, Xu S, Zhan X, Wu B. In Vitro Study of Dentin Hypersensitivity Treated by $980-\mathrm{nm}$ Diode Laser 2013;4(3):111-9.

27. Brugnera Jr A, Garrini AE, Pinheiro AL, Campos DH, Donamaria E, Magalhaes F, et al. LLLT in treating dentinary hypersensibility: a histologic study and clinical application. InLasers in Dentistry IX 2003;4950):46-53. International Society for Optics and Photonics.

28. Matsumoto K. Study on the treatment of Hypersensitive dentine GaAlAs laser diode. Jpn J Conserv Dent. 1985;28:766-71.

29. Kumazaki M, Zennyu K, Inoue M, Fujii B. Clinical evaluation of GaAlAs-semiconductor laser in the treatment of hypersensitive dentin. Japanese Journal of Conservative Dentistry 1990;33:911-8.

30. Aun CA, Brugnera Júnior A, Villa RG. Raio laserHipersensibilidade dentinária. Revista da APCD 1989;43(2):65-8.

31. Nandakumar A, Iyer VH. In vitro analysis comparing efficacy of lasers and desensitizing agents on dentin tubule occlusion: a scanning electron microscope study. International Journal of Laser Dentistry 2014;4(1):1.

32. Jain PR, Naik GD, Uppor SA, Kamath DG. Diode laser and fluoride varnish in the management of dentin hypersensitivity 2015;(2).

33. Pi I, Ta E, Ct B, Asa M, Mohammed A, Asa M, et al. MedPub Journals Dentine Hypersensitivity : Review of a Common Oral Health Problem Abstract 2017, 1-7. 